\title{
LA LAGUNA, ENERO DE 1987
}

\author{
Begoña Ortega Villaro \\ Universidad de Burgos \\ bortegav@ubu.es
}

Cuatro jóvenes, de tres universidades distintas, comenzábamos nuestra carrera académica en La Laguna: Miguel Ángel Rábade, Francisca Plaza Picón, Isabel García Gálvez y yo. Nuestro entusiasmo cubría de sobra la distancia y la lejanía del entorno hasta entonces conocido. Eran los tiempos en los que La Laguna ofrecía una salida a las dificultades laborales de la península. Llevaba tiempo siéndolo pero, por fortuna, aquella generación y las siguientes iban a constituir un cambio trascendente, pues ya no iban a utilizar la universidad canaria como trampolín, sino como hogar, empeñando sus esfuerzos para formar y consolidar una universidad de calidad, un lugar que docentes y alumnos sintieran suyo. Yo, recién licenciada, con mi tesina aún fresca en el bolsillo y con poco más que mis apuntes de la carrera para enfrentarme a la Lingüística Indoeuropea de tercero de Filología Clásica, llegué a aquel laberíntico edificio nerviosa y abrumada por la responsabilidad. Me acogieron, comprensivos y amables, los profesores que allí luchaban por dotar a La Laguna de una incipiente carrera de Clásicas que diese una buena formación a los muchos alumnos que por entonces tenían esos estudios. Pero mi cobijo en aquellos primeros meses de desconcierto, descubrimiento y aprendizaje, laboral, académico y, sobre todo, vital, fueron aquellos tres andaluces que me enseñaron tanto del modo de ser del sur, de otras tierras, otros acentos, otras sensibilidades, también de otros maestros y otras inquietudes académicas. Isabel y yo compartíamos nuestra preferencia por la Filología Griega, y en aquellos primeros momentos, por la Lingüística, que orientaba nuestros proyectos de tesis doctoral. Pero ya se adivinaba en ella que su amor no iba a estar en el uso de $\delta \in \hat{\imath}$ en Aristófanes, que ya había llenado varios ficheros verdes en su mesa, sino en la lengua y cultura neogriega con la que había entrado en contacto en una beca de verano. En Granada estaban ya superando el prejuicio de que aquel territorio solo podía, e incluso debía, ser un hobby de vacaciones para los clásicos, pero en Valladolid, de donde yo venía, aún faltaba tiempo para que el griego moderno lograse su espacio propio en los Estudios Clásicos. Ante mí y mi mentalidad un tanto pacata, Isabel desplegó todo lo que ella intuía de riqueza y descubrimiento, y me inculcó un respeto por ese campo que aunque no he formalizado en ningún estudio quizá haya sido el germen de mi posterior incursión en los estudios bizantinos.

Ese fue un regalo que Isabel me hizo, el más académico. Pero quizá no hubiera existido sino hubiera estado acompañado por algunos momentos que conservo como encapsulados en un gota de ámbar, cuando se desplegaba ante mí una personalidad 
fuerte y decidida a pesar de la dulzura de su voz y de sus ojos claros: una final de baloncesto, el deporte que entonces practicaba ella, en la única tele disponible en aquellos pisos de casi estudiantes, las coplas con las que de vez en cuando se arrancaba por sorpresa, y a las que me aficionó ya para siempre, las reflexiones sobre las personas que entonces conocimos, sus confesiones sobre su modo de ser y de pensar, que entonces compartíamos con la generosidad propia de aquella edad.

Yo me marché de La Laguna a final de aquel curso, pero ellos se quedaron a construir su vida académica y personal allí. Aquellos primeros meses fueron, para ellos, una etapa más, la inicial, de su evolución y, como ellos, fueron transformándose en la vida que iban viviendo a medida que los años transcurrían. Mantuvimos el contacto esporádicamente porque nuestras carreras académicas tampoco confluyeron, ni en su desarrollo ni en sus áreas de interés. Por ello para mí aquel tiempo se quedó guardado en un rincón decisivo de mis vivencias, las que me formaron tal y como soy. Cuando muchos años después Isabel me llamó para invitarme a La Laguna a dar una conferencia, sentí la emoción temerosa de volver a ese lugar especial que casi nunca se corresponde con el que guardamos en el corazón. No nos habíamos vuelto a ver desde hacía casi 20 años, pero Isabel seguía igual, en su entusiasmo por su trabajo, en esa dulzura con la que seguía envolviendo su firme criterio. Le agradecí que me hubiese dado la oportunidad de recuperar aquel territorio añorado, aunque tantas cosas hubiesen cambiado, desde el edificio a los jóvenes profesores que allí estaban. Prometimos no perder la relación, cuando quizá pudiéramos hacer coincidir, aunque fuera muy tangencialmente, nuestros intereses académicos. Pero las urgencias del día a día siempre nos superan, hasta que la noticia de su fallecimiento convirtió

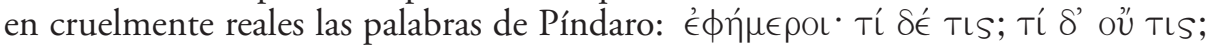

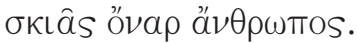

Somos personas afortunadas, los profesionales que nos dedicamos a lo que nos gusta. Por muy complicados que sean los procesos de la docencia, de la investigación, del reconocimiento de nuestra labor, siempre encontramos la satisfacción de aprender sin cesar, de encontrar caminos nuevos, o viejos caminos que nos llevan a lugares distintos. En mi caso, he tenido la fortuna de que esos nuevos o viejos caminos los he recorrido acompañada por un puñado de personas extraordinarias, que me han regalado sus conocimientos, su entusiasmo, su amistad. Isabel fue una de las primeras en hacerlo, y siempre la notaré presente, tarareando "Ojos verdes" antes de recitarme un poema de Seferis. Tus muchas publicaciones, tus iniciativas en pro de los estudios neogriegos, estarán siempre ahí, pero también el poso que dejaste en los que tuvimos la fortuna de coincidir contigo. Gracias, Isabel. 